\title{
The Impact of Individual, Competitive, and Collaborative Mathematics Game Play on Learning, Performance, and Motivation
}

\author{
Jan L. Plass \\ New York University
}

\author{
Paul A. O'Keefe \\ New York University and The City University of New York \\ Elizabeth O. Hayward, Murphy Stein, and \\ Ken Perlin \\ New York University
}

\author{
Bruce D. Homer and Jennifer Case \\ The City University of New York
}

\begin{abstract}
The present research examined how mode of play in an educational mathematics video game impacts learning, performance, and motivation. The game was designed for the practice and automation of arithmetic skills to increase fluency and was adapted to allow for individual, competitive, or collaborative game play. Participants $(N=58)$ from urban middle schools were randomly assigned to each experimental condition. Results suggested that, in comparison to individual play, competition increased in-game learning, whereas collaboration decreased performance during the experimental play session. Although out-of-game math fluency improved overall, it did not vary by condition. Furthermore, competition and collaboration elicited greater situational interest and enjoyment and invoked a stronger mastery goal orientation. Additionally, collaboration resulted in stronger intentions to play the game again and to recommend it to others. Results are discussed in terms of the potential for mathematics learning games and technology to increase student learning and motivation and to demonstrate how different modes of engagement can inform the instructional design of such games.
\end{abstract}

Keywords: achievement goal orientations, games, learning

The past decade has seen an intensifying interest in the use of digital games in pursuit of educational goals. Entertainment games, whether they run on a computer, game console, mobile device, or touch pad, are highly engaging and motivating, and educators have suggested taking advantage of these qualities of

This article was published Online First September 9, 2013

Jan L. Plass, Games For Learning Institute (G4LI) and Consortium for Research and Evaluation of Advanced Technologies in Education (CREATE), New York University; Paul A. O'Keefe, G4LI and CREATE, New York University, and The Graduate Center, The City University of New York; Bruce D. Homer and Jennifer Case, G4LI and Program in Educational Psychology, The Graduate Center, The City University of New York; Elizabeth O. Hayward, Murphy Stein, and Ken Perlin, G4LI and Department of Computer Science, Courant Institute of Mathematical Sciences, New York University.

Paul A. O'Keefe is now at the Department of Psychology, Stanford University.

The work reported in this article was funded in part by a grant from Microsoft Research to the G4LI. The content and opinions herein are the authors' and may not reflect the views of Microsoft Research, nor does mention of trade names, products, or organizations imply endorsement. Jan L. Plass and Paul A. O'Keefe contributed equally to this work. We thank the G4LI research assistants who assisted in the data collection for this research.

Correspondence concerning this article should be addressed to Jan L. Plass, New York University, CREATE, 196 Mercer Street Suite 800, New York, NY 10012, or Paul A. O'Keefe, Department of Psychology, Jordan Hall, Building 420, 450 Serra Mall, Stanford University, Stanford, CA 94305. E-mail: jan.plass@nyu.edu or paul.okeefe@stanford.edu games to facilitate learning (Gee, 2007; Kafai, 1995; Squire, 2003). Proponents of digital game-based learning have argued that well-designed games embody educational and learning theory and are in line with some of the "best practices" of education (e.g., Barab, Ingram-Goble, \& Warren, 2008; Collins \& Halverson, 2009; Gee, 2003; Mayo, 2007; Shaffer, 2008; Squire, 2008).

The validation of claims that good games are good for learning first leads us to consider the question: What is a good game? There are many aspects of the design of a digital game that can impact the game's educational effectiveness. For example, game designers make decisions regarding the game's core mechanic (Plass et al., in press; Salen \& Zimmerman, 2003), the representation of the game content (Plass et al., 2009), the emotional design of the game (Um, Plass, Hayward, \& Homer, 2012), the game's incentive system, and social aspects of play (Salen \& Zimmerman, 2003). Research on the design of good games for learning therefore examines the effects of key features of games on students' learning experiences and outcomes (Plass, Homer, \& Hayward, 2009). The goal of this line of research is to investigate whether effects of social, cognitive, and affective factors related to learning found in research on other learning environments can be extended to the design of games for learning and used to develop theory-based, empirically validated design patterns for such games. Design patterns, originally proposed in the context of architecture (Alexander, Ishikawa, \& Silverstein, 1977), represent general solutions to commonly occurring problems that educational game designers can use to guide the design of specific aspects of their games.

In the present study, we examined one of these design patterns - the context of playing a game- to increase arithmetic flu- 
ency. Middle-school students were randomly assigned to play an arithmetic game, FactorReactor, developed by the Games for Learning Institute for the purpose of this research. They played either on their own (individual), against another student (competitive), or together with another student (collaborative). Learning, performance, achievement goal orientations, interest, enjoyment, and future game intentions were examined as a function of mode of play.

\section{Theoretical Background}

In the present research, we were interested in how three modes of play (individual, competitive, and collaborative) affect learning, game performance, and motivation. The conceptual framework for this research consists of the educational context of learning, achievement goal theory, and interest for which we review related research in this section.

\section{Educational Contexts}

It has long been established that social context generally, and peer interaction specifically, impact the learning process and that knowledge construction is a social, collaborative process (Light \& Littleton, 1999; Piaget, 1932; Salomon, 1993; Scardamalia \& Bereiter, 1991; Vygotsky, 1978). Research on the social context of learning has found that peer involvement in learning can affect both academic achievement as well as learner attitudes in a variety of contexts. Early work on cooperative learning in the classroom context suggests that peer collaboration may have positive effects on academic achievement across a variety of content areas (Berg, 1994; Dillenbourg, 1999; Slavin, 1980, 1983; Slavin, Leavey, \& Madden, 1984). Cooperative learning has also been found to increase positive attitudes toward school generally and mathematics as a subject area (Slavin, 1980; Slavin et al., 1984). Research on competition suggests that learning and performance are better in competitive compared with individual settings (Ames, 1984) and that competitive features result in the development of analytic skills (Fu, Wu, \& Ho, 2009), but not always in increased learning outcomes (Ke \& Grabowski, 2007).

\section{Collaboration}

Group collaboration can take a variety of forms and has been investigated in a broad range of contexts, including classroombased learning (Berg, 1994), computer-based learning (R. T. Johnson, Johnson, \& Stanne, 1986; Mevarech, Stern, \& Levita, 1987; Scardamalia \& Bereiter, 1991), and web-based and e-learning (Hron \& Friedrich, 2003). What these collaborations have in common is that two or more learners interact in a synchronous form to negotiate shared meaning and jointly and continuously solve problems (Dillenbourg, 1999).

The recent surge in interest in digital games as tools for learning offers up a new forum for investigating learning as a social activity. Initial research has provided thick descriptions and case studies of such collaborative activities in learning with games and related activities (Barab, Thomas, Dodge, Carteaux, \& Tuzun, 2005; Squire, 2005; Steinkuehler, 2006). In comparison to individual study, group collaboration appears to be well suited for problem solving because collaboration encourages students to ex- plain their thinking, verbalize it, and engage in joint elaboration on their decision making (Mullins, Rummel, \& Spada, 2011). In addition, Kirschner, Paas, Kirschner, and Janssen (2011) showed that students working in small groups were better able to handle the cognitive load demands of problems with complex information, and thus learned more efficiently, than students solving problems in individual work.

The effects of collaboration only accrue, however, when certain conditions are met. In fact, a meta-analysis by Lou et al. (1996) found that collaboration did not have an effect in about one fourth of the studies, and in some cases even had a negative impact. Some of the conditions for the effectiveness of group collaboration are so fundamental that many consider them part of the definition of collaborative learning: Group members must have a shared group goal that they deem important, and the success of the activity must depend on all members of the group; that is, each member must be individually accountable (Slavin, 1988).

In addition to these fundamental conditions, additional ways to support group collaboration have been explored. Berg (1994), for example, used collaboration scripts to facilitate group collaboration, and Hron, Hesse, Cress, and Giovis (2000) showed that structuring the dialogue in group collaboration enhanced learners' orientation to the subject matter and reduced off-task conversation, though it did not increase knowledge gains. Other ways to assure the success of collaborative learning includes providing students with visualization tools (Fischer, Bruhn, Gräsel, \& Mandl, 2002), managing the cognitive load they experience (van Bruggen, Kirschner, \& Jochems, 2002), and providing adaptive support from intelligent tutors (Diziol, Walker, Rummel, \& Koedinger, 2010) and from interactive dialogue agents (Chaudhuri et al., 2008).

The beneficial performance effects of collaboration only appear to be present for tasks involving conceptual knowledge, but not for procedural skill fluency (Mullins et al., 2011). In their research, Mullins et al. (2011) found that collaboration improved learning for both conceptual and procedural (skill fluency) material but that students in the procedural skill task engaged in ineffective learning behaviors. This is supported by other studies of group collaboration on learning involving conceptual knowledge that found that students provide explanations to one another (Diziol, Rummel, Spada, \& McLaren, 2007) and engage in joint elaboration and co-construction of knowledge (Berg, 1994). The same kind of elaboration was not found in procedural skills acquisition.

In the present study, we were interested in investigating collaboration on a game-based task of arithmetic fluency development. Even though research so far has not shown clear benefits of collaboration for skills automation, other research suggests that conceptual knowledge and skills acquisition are linked, and the development of one can benefit the other (Rittle-Johnson \& Alibali, 1999; Rittle-Johnson, Siegler, \& Alibali, 2001).

Arithmetic skills development begins in early childhood and continues throughout formal and informal schooling with the goal of becoming automated, but even adults often still use strategies to solve basic problems of addition, subtraction, multiplication, and division rather than retrieving basic arithmetic facts from longterm memory (Tronsky, 2005). The adaptive strategy choice model developed by Siegler and colleagues (Lemaire \& Siegler, 1995; Shrager \& Siegler, 1998) describes the development of strategy use along four dimensions as arithmetic experience increases. These dimensions include (a) which strategies are available to the 
learner, (b) when a particular strategy is used, (c) how that strategy is executed, and (e) the decisions governing which strategy is chosen. As learners encounter arithmetic problems, they select and carry out a strategy to solve the problem and, in the process, accumulate data on the effectiveness of their strategy on multiple levels (Shrager \& Siegler, 1998). Research has shown that, over time, automation (i.e., retrieval of the correct answer from memory) becomes the dominant strategy because it yields highest accuracy rates and shortest response times (Tronsky, 2005).

FactorReactor was designed to support this skill automation in middle-school-age children by providing arithmetic problems that increase in difficulty from one level to the next. Small-group collaboration was found to be beneficial in the classroom even for the development of arithmetic skills (Yackel, Cobb, \& Wood, 1991), and we were interested in whether a collaborative mode in the game would result in higher performance compared with an individual play mode.

\section{Competition}

A common element of video games is a competitive mode in which players compete with one another. In some cases, this competition means that two or more players compete for the same goal, such as in the table tennis game in Wii Sports Resort. In other cases, both players play the same game individually but are aware of each other's progress and score, such as in the bowling game in Wii Sports Resort.

Many studies investigating the effect of competitive forms of learning compare various social modes with an individual mode. A meta-analysis of 122 studies, comparing the effects of individual, competitive, and collaborative goal structures on achievement, found benefits for collaborative compared with competitive or individual goal structures (D. W. Johnson, Johnson, Maruyama, Nelson, \& Skon, 1981). In a related study, R. T. Johnson, Johnson, and Stanne (1986) compared the effect of computer-assisted cooperative, competitive, and individual learning on performance and attitudes. Eighth graders were randomly assigned to work in either a small group, in the cooperative and competitive conditions, or individually to learn about fundamentals of map reading and navigation. Students in the cooperative condition were found to show the highest performance on daily worksheets. However, both the cooperative and competitive groups had higher levels of interest in computers at the close of the study, as compared with those who worked individually. More recently, Fu et al. (2009) investigated the knowledge creation process in a web-based learning environment concerning computer software. The authors predicted that the social presence of peers, in the form of a partner, would increase performance as well as enjoyment motivation. Four conditions were compared in which the collaborative (presence vs. absence of a partner) and competitive (presence vs. absence of financial reward and grade feedback) features of group learning of undergraduate students were systematically varied. Results indicate that both the collaborative and competitive features increased enjoyment in learning. When competitive features were present, students demonstrated higher analytic skills, or the separation of concepts into component parts as a means to understand organizational structure, as defined by Bloom's (1956) taxonomy. The collaborative feature encouraged higher synthetic skills, or the building of structure from information, and therefore was indica- tive of higher level learning. The authors concluded that both collaborative and competitive elements worked to bolster performance in a web-based environment.

Strommen (1993) compared cooperative and competitive contexts in learning from a computer-based natural science game among fourth graders. Students in the collaborative condition were found to be more successful in their game performance and used more game play strategies as compared with those in the competitive condition. Ke and Grabowski (2007) used a math computer game addressing measurement, whole numbers, equations, and graphing to examine the impact of cooperative game play, individual play, and competitive game play in fifth graders. After eight 40-min game play sessions, there was no difference between the cooperative and competitive conditions in achievement, as measured by multiple-choice arithmetic test. However, students in the cooperative condition demonstrated more positive math attitudes at the close of the study as compared with those in the competitive condition, further suggesting that the presence of peers when learning impacts attitudes toward academic content.

Because competition is a common element of games, and because some research suggests that performance is better in competitive compared with individual settings (Ames, 1984), we were interested in how learning and performance in the competitive play version of FactorReactor compared with individual play.

\section{Achievement Goal Orientations}

The structure of learning environments and the tasks used to engage learners can elicit particular achievement goals that can either facilitate or hinder learning (Ames, 1992; Meece, Anderman, \& Anderman, 2006). Similarly, modes of play may influence the adoption of particular goal orientations. Achievement goal theory posits two major types of goal orientations people endorse in achievement situations: mastery and performance (Ames \& Archer, 1988; Dweck \& Leggett, 1988; Elliot, 2005). A mastery goal orientation focuses on learning and the development of abilities, and success is defined in terms of personal improvement. In contrast, performance goal orientations focus on demonstrating or validating abilities, and success is defined in terms of performing well compared with others (Elliot, 1999, 2005). It is distinct from competition, however, in that outperforming others is a means of demonstrating or validating abilities rather than being the goal in and of itself. Performance goals can further be subdivided into approach and avoidance dimensions (Cury, Elliot, Da Fonseca, \& Moller, 2006; Elliot, 2005; Elliot \& McGregor, 2001). A performance-approach goal orientation focuses on performing wel compared with others, whereas a performance-avoidance goal orientation is concerned with evading the appearance of incompetence and performing poorly relative to others. This approachavoidance distinction has also been made with regard to mastery goals (Elliot, 1999; Elliot \& McGregor, 2001); however, there is less empirical support for it (Maehr \& Zusho, 2009). Therefore, we used the trichotomous model in the present research, assessing mastery-approach (which we refer to as mastery), performanceapproach, and performance-avoidance goals among learners.

In general, research has found that mastery goal orientations result in highly adaptive patterns of motivation and learning (Midgley, Kaplan, \& Middleton, 2001). For example, they are associated with high levels of effort and persistence (Grant \& 
Dweck, 2003), particularly on difficult tasks (Elliott \& Dweck, 1988; Stipek \& Kowalski, 1989), increased task involvement (Harackiewicz, Barron, Tauer, Carter, \& Elliot, 2000), and increased self-efficacy (Meece, Blumenfeld, \& Hoyle, 1988; Midgley et al., 1998). Moreover, mastery goal orientations are associated with enhanced learning strategies that lead to better understanding of concepts and recall (Ames \& Archer, 1988; Elliot \& McGregor, 2001; Grant \& Dweck, 2003). Although performance-approach goals can also have adaptive outcomes, such as high academic achievement (Harackiewicz, Barron, Pintrich, Elliot, \& Thrash, 2002), these benefits can be accompanied by test anxiety (Linnenbrink, 2005; Skaalvik, 1997), cheating (Tas \& Tekkaya, 2010), and the avoidance of help seeking (Karabenick, 2004). In contrast, performance-avoidance goals are consistently found to result in maladaptive motivational outcomes (Elliot \& Mapes, 2005; Harackiewicz et al., 2002; Midgley et al., 2001). They are associated with lower achievement, intrinsic motivation, academic selfefficacy, and engagement (e.g., Church, Elliot, \& Gable, 2001; Elliot \& McGregor, 1999; Middleton \& Midgley, 1997; Pekrun, Elliot, \& Maier, 2009; Skaalvik, 1997).

Taken together, mastery goal orientations provide the most adaptive framework from which to pursue educational goals, and contexts structured to invoke these goals have the potential to benefit student motivation in the long run. For example, O'Keefe, Ben-Eliyahu, and Linnenbrink-Garcia (2013) found that a masterystructured learning environment not only attenuated students' performance-approach and -avoidance goal orientations but also augmented mastery goal orientations. Furthermore, the observed increases in mastery goal orientations were sustained 6 months after students had returned to more traditional, performanceoriented learning environments.

In the present research, we examined how playing an educational game by oneself, in competition with another, or collaboratively results in the adoption of various achievement goal orientations. Given their influence on the adaptiveness of motivational and learning patterns, in the present study we intended to shed light on how the design and implementation of educational games can result in optimal motivational outcomes. A study by Ames (1984) found that working individually on a set of puzzles led children to attribute their level of performance to the effort they had expended, whereas those working competitively attributed their performance to their level of ability. Given that these attributional patterns map onto mastery and performance goal orientations, respectively (Dweck, 1986; Dweck \& Leggett, 1988), we might expect that performance goal orientations would be adopted more strongly in the competitive condition relative to the individual play condition. The context of a game, however, may change the meaning of competition. Although games can heighten concerns about performance, they do not necessarily heighten concerns about the demonstration or validation of normative ability. Instead, educational games, such as the one employed in the present research, are designed to produce incremental personal success, which is in line with a mastery goal orientation. Therefore, we expected that playing competitively would increase mastery goal orientations as compared to individual play and that performance goal orientations would not be affected by the competitive game context.

We expected the collaborative condition to have a similar effect on players' mastery goal orientations. A study by Ames and Felker (1979) examining children's attributions regarding the achieve- ment outcomes of another student found that ability attributions were stronger for those who worked individually and competitively than collaboratively. Similarly, effort attributions were stronger for individual and competitive work than successful (as compared with unsuccessful) collaborations. These results would suggest an ambiguous prediction regarding the adoption of achievement goal orientations in the types of contexts that are traditionally examined. However, the context of an educational game is different than the nongame contexts that are typically studied, largely because it provides a framework for incremental personal improvement. Accordingly, we expected that collaborative play would invoke stronger mastery goal orientations compared to individual play, and that performance goal orientations would remain unaffected.

\section{Interest}

Mode of play should similarly have an impact on players' interest in the game. First, it is useful to distinguish two general types of interest. Individual interest refers to an intrinsic desire and tendency to engage in particular ideas, content, and activities over time. For example, someone with an individual interest in sports may watch games on television, read up on player stats, or play in a competitive athletic league, and engage in these activities on a relatively regular basis. Situational interest, in contrast, refers to the attentional and affective reactions elicited by the environment (e.g., Hidi \& Renninger, 2006; Linnenbrink-Garcia et al., 2010). For instance, a physics instructor explaining how rockets work may not elicit much situational interest in his or her students using traditional lecture methods; however, he or she would likely elicit high situational interest by having students build and launch their own rockets. Although situational interest involves elements that include feelings of excitement and fascination, it is distinct from other constructs, such as enjoyment, in that it also includes elements relating to the personal value of the interest object or involvement in the activity.

Situational interest is of particular importance in education because it is essential to the development of individual interest. According to Hidi and Renninger's (2006) four phase model, once situational interest is triggered, it can be maintained when personal relevance or involvement is established. Individual interest begins to emerge when the individual develops a relatively persistent predisposition to reengage in particular ideas, content, or activities. Finally, well-developed individual interest emerges once contextual supports are no longer necessary, such that the interest is generally, but not exclusively, self-generated. In the present study, we were interested in how the modes of play, particularly competitive and collaborative, influence situational interest, as it may suggest how games for learning can be designed and implemented to effectively elicit situational interest, and ultimately develop into individual interest in academic topics.

Although one of the defining characteristics of games is to elicit situational interest (Salen \& Zimmerman, 2003), the extent to which individual, competitive, and collaborative modes of play contribute to its invocation has not yet been examined experimentally. We expected that competitive and collaborative play modes would elicit greater situational interest than playing alone due to the social aspect of playing against or with a partner. These social contexts should enhance the excitement of game play, as well as 
personal involvement. Additionally, we expected that other indicators of interest and motivation would reflect this prediction, such that the competitive and collaborative conditions should lead to greater enjoyment of the game, as well as a greater likelihood of future game reengagement and recommending the game to others.

\section{The Present Study}

In the present study, we aimed to investigate how three modes of play (individual, competitive, and collaborative) affect learning, game performance, and motivation. As discussed above, social educational contexts, such as competition and collaboration, have been shown to affect learning in a variety of settings, such as classrooms and web-based environments, for different age groups, and for different levels of learning objectives. It is of great interest to game designers and motivation theorists alike whether similar effects can be found for digital games designed for educational purposes. We, therefore, investigated how competitive and collaborative modes of play compared with individual play in impacting learning, performance, achievement goal orientations, situational interest, enjoyment, and intentions to reengage in the game and recommend it to others. Our focus on these outcomes reflects the important intentions of using games for educational purposes, such that they have the potential to improve performance and increase engagement in educational activities. For the present research, we used FactorReactor, a game designed to practice and automate arithmetic skills to increase arithmetic fluency in middle-schoolage students.

\section{Method}

Participants. Participants were 58 sixth-, seventh-, and eighth-grade students ( $58.6 \%$ female) from seven urban public schools in a major northeastern city. All students were taking part in a technology-themed afterschool program led by a teacher at their school. Membership in each of the programs was small and voluntary. In partnership with these programs, researchers made weekly visits to each school during the academic year to introduce students to educational technologies and games. In one of the sessions, students participated in the present study. The mean age of the students was 11.02 years $(S D=3.61)$. Missing data were handled through listwise deletion.

Procedure. Before students arrived to the classroom in which the study was run, tables were arranged so that computer stations could be set up sufficiently far apart from one another. When students arrived, their assent and parental consent was collected, and were then seated at a computer station. They first watched an instructional video on their computers that provided an overview of the rules and goals of the game, FactorReactor, as well as how to use the Xbox game controller. Computer monitors were either 13 or 15 in. (33 or $38.1 \mathrm{~cm}$ ). All participants then played a practice round of the game individually for $5 \mathrm{~min}$. During this time, they were provided with a controller schematic sheet to assist in learning the operation of the controller. At the end of the practice session, an experimenter was available to the students to clarify any issues regarding the game, and the controller schematic sheet was taken away. Next, all participants played the game independently for $3 \mathrm{~min}$, which constituted the pretest of game performance.
Students were then randomly assigned to one of three modes of play: individual $(n=16)$, competitive $(n=20)$, and collaborative $(n=22)$. This also meant that partners in the competitive and collaborative conditions were random. Participants in the individual condition were situated in front of a laptop computer with a single controller, whereas the competitive and collaborative conditions joined with a partner in front of a laptop computer with two controllers. Before beginning, an experimenter provided the context for the experimental game play and specific instructions to the students. Those in the individual condition were told that they would be playing the same version of the game as before and were given the following instructions: "When playing the game, get the best score you can." Those in the competitive condition were told that they would be playing a version of the game that allowed two players to compete against each other and were given the following instructions: "When playing the game, compete against each other for the better score." Those in the collaborative condition were told that they would be playing a version of the game that allowed two players to play together and were given the following instructions: "When playing the game, work together to get the best score." Instructions to learners regarding how to collaborate were kept relatively short for three reasons: First, middle-schoolage students are used to playing games without receiving elaborate instructions and would likely have skipped any instructions provided to them. Second, models of mathematics learning describe students as active learners who spontaneously create their own strategies to solve a problem (Cobb, Wood, \& Yackel, 1991), and we did not want to stifle this invention of strategies by prescribing the process of collaboration. Finally, critical reviews of studies involving various forms of scaffolding have argued that performance differences between the individual and collaborative group found in such studies could have been attributable to the fact that the scaffolding (elaboration scripts, dialogue scaffolding, visualizations) was only given to the collaborative group (Mullins, Rummel, \& Spada, 2010).

Participants were given 15 min to play, at which point the game automatically stopped. Figure 1 shows screen shots of the game in the three play modes. Participants then played another 3-min individual play session as a posttest of game performance. At the end of game play, participants were independently administered surveys assessing game-relevant achievement goal orientations, situational interest in the game, game enjoyment, future intentions regarding the game, and their degree of experience with video game controllers. Finally, they completed another individual 3-min play session.

\section{Materials}

FactorReactor. FactorReactor is a game designed to practice and automate arithmetic skills, and was adapted from the original version to investigate cognitive and motivational outcomes related to mode of play. The game runs on a PC and is played with an Xbox controller connected to the PC via USB cable. Figure 1 shows screen shots of the game for each mode of play. Arithmetic fluency was chosen because it was identified by many teachers in our collaborating middle schools as a key skill on which other skills from the common core standards in Grades 6-8 build, but which is not sufficiently developed in many middle-school students. 
A) Single Player

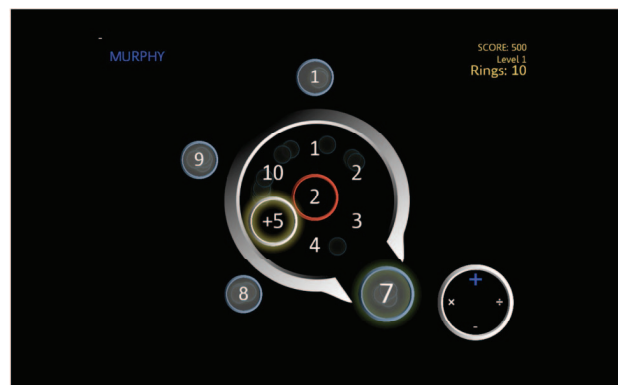

B) Competitive

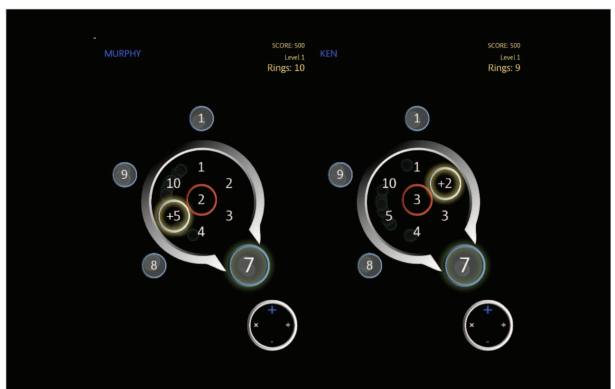

C) Collaborative

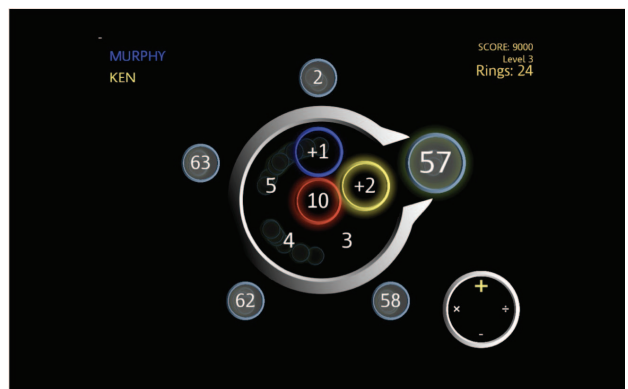

Figure 1. Three modes of play in FactorReactor: A: individual play. B: competitive play. C: collaborative play. FactorReactor by Murphy Stein and Games for Learning Institute is licensed under a Creative Commons Attribution-NonCommercial-ShareAlike 3.0 unported license.

FactorReactor possesses the key defining elements of a game: It has a clear goal and clear rules of play, has an engaging game mechanic that allows for a high degree of player choice, provides feedback and incentives, and has a fail state (Salen \& Zimmerman, 2003). The object of the game was to transform the center number into one of the surrounding goal numbers by adding, subtracting, multiplying, or dividing it by one of the numbers from the inner ring. This was conducted by selecting one of the operators $(+,-$, $\times, \div)$ and one of the inner numbers and then hitting the fire button. For example, if the goal number was 7 and the center number was 2, as it is in Figure 1A, the player might select 5 from the inner ring, and then choose the "+" operator. By pressing the fire button, 5 would be added to the center number, transforming it to 7. A subsequent press of the fire button then solved the problem and automatically advanced to the next goal number. When transformations were done correctly, the center ring turned from red to green. If incorrect or impossible transformations were attempted (e.g., dividing the center number so that it does not result in a whole number, such as $2 \div 5$ ), the center number would temporarily glow and jiggle. Players had full control over which goal number they worked on at any given time, however, affording considerable flexibility in solving each problem.

Each time the center number was correctly transformed, the player earned a token, called a "ring," and each player began the game with 10 rings. The number of rings rewarded for a correct transformation was equal to 2 times the minimum possible number of transformations for the relevant solution. Players could be awarded between two and eight rings, depending on the problem that was solved (i.e., problems required, at a minimum, between one and four steps to be solved). Rings are used up with each operation, such that when a player hits the fire button, a ring is used; therefore, if a player attempts to transform the center number using multiple operations, multiple rings are used. In this way, the game disincentivized players from reaching their goal by guessing or repeating the same simple operation again and again (e.g., repeatedly subtracting a small number) and encouraged them to use more complex operations to solve problems in fewer moves. Scores were also calculated, which were highest for those who solved each problem using the least amount of rings. The level ended when all goal numbers were computed properly and at least one ring remained.

Levels increased in difficulty, such that the operations needed to reach the goal number became more complex. For example, a player may not be able to simply subtract an inner-ring number to successfully transform the center number as in easier levels. They may instead need to divide by one inner-ring number and then add another inner-ring number, or perhaps a more complex series of transformations. When a player ran out of rings, they received a "Game Over" message and were required to start the current level from the beginning. These messages were therefore an indicator of the use of inefficient strategies used by the players to solve the arithmetic problems presented by the game.

The game screen for the individual and collaborative play conditions were nearly identical (see Figure 1A and 1C). They had one game interface, which included one center number, five inner-ring numbers, and five goal numbers. The only difference between the 
two was that, in the collaborative condition, both players had simultaneous and independent control over the game operations. That is, each player could select operators, inner-ring numbers, goal numbers, and also hit the fire button. Furthermore, player names were displayed in the upper-left portion of the screen, and in the upper-right portion of the screen were indicators of game performance, which included their current score, level, and number of rings. In the competitive condition, players had their own game interfaces, which were placed side-by-side (see Figure 1B). Each interface was identical to the individual play condition; however, indicators of each player's game performance were present and visible to both players. Furthermore, both players could work at their own pace, independently advancing through the levels.

\section{Measures}

Within-game learning and performance measures. Two indicators of game performance were used. Within-game learning was assessed with the total number of problems solved during the posttest individual game play period. During this game period, players were presented with problems on a similar level of difficulty as during the pretest and experimental sessions. The number of problems they solved, and the challenge level they reached, depended on how fast they progressed in the game. Increased performance during the posttest should suggest that arithmetic learning had occurred during the experimental session. The other indicator was the total number of "Game Over" messages players received during the experimental game play. When a player ran out of rings, he or she received a message stating, "You ran out of rings. The FactorReactor was destroyed," and then players restarted the level, which contained the same problems. Players ran out of rings either because they failed to solve any problems correctly, thereby failing to earn rings, or because they were not efficient enough in solving the problems. Therefore, the number of times a player received this "Game Over" message was also considered indicative of game performance. Pretest performance for each indicator was also collected and used as covariates in the analyses.

Achievement goal orientations. Participants were given the Achievement Goal Orientation subscale from the Patterns of Adaptive Learning Scales (Midgley et al., 2000). The language in the scale was simplified to ensure comprehension in our middleschool sample and was adapted to be relevant for game play. The 14-item survey asked students to indicate their level of agreement using a 7-point scale $(1=$ Very much disagree, $4=$ Neither agree nor disagree, $7=$ Very much agree) in response to items such as "One of my goals was to learn as much as I could about the game" (mastery; $\alpha=.87$ ), "One of my goals was to show others that the game was easy for me" (performance-approach; $\alpha=.84$ ), and "It was important to me that my performance on the game didn't make me look stupid" (performance-avoidance; $\alpha=.70$ ).

Situational interest. Situational interest was measured using an adaptation of the Situational Interest Survey (LinnenbrinkGarcia et al., 2010). The language of the survey was simplified to ensure comprehension in our middle-school sample and was adapted to be relevant for game play. The survey assessed several aspects of situational interest, including affective responses to the game (e.g., excitement, fascination) and its personal importance. Participants used a 7-point scale anchored at 1 (Very much dis- agree), 4 (Neither agree nor disagree), and 7 (Very much agree) to indicate their level of agreement with 12 statements, such as "The game was exciting," "I learned valuable things from the game," and "What I learned from the game is fascinating to me" $(\alpha=.92)$.

Game enjoyment. Overall enjoyment of the game was assessed with two questions asking participants to rate the extent to which they had fun playing the game and how much they liked the game, on a 5-point scale anchored at 1 (Not at all) and 5 (A lot) $(\alpha=.80)$.

Future game intentions. Two items assessed participants' future intentions regarding FactorReactor. The first assessed intentions to reengage in the game, asking "Would you play this game again in the future?" The other assessed their intention to recommend the game to someone else, asking "Would you recommend it to your friends/teachers?" Both items were assessed on a 5-point scale ranging from 1 (Not at all) to 5 (Definitely).

Prior experience with video game controllers. Participants were asked to indicate their level of experience with video game controllers like the ones used in the study, rated on a 5-point scale anchored at 1 (None) and 5 ( $A$ lot). This variable was used as a covariate on the game performance analyses (see Table 1).

Out-of-game learning measure. Participants were given a pre- and posttest of math fluency as an out-of-game assessment of arithmetic learning. The measure included 160 simple arithmetic problems for which participants were given $3 \mathrm{~min}$ to complete as many problems as possible. This measure of math fluency was adapted from the Woodcock-Johnson III Math Fluency subtest (McGrew \& Woodcock, 2001), modified by randomizing the presentation of problems and by including simple division problems as well as addition, subtraction, and multiplication problems. The posttest of math fluency was identical to the pretest, though the problems were presented in a different, randomized order to diminish practice effects.

\section{Results}

The data were analyzed using hierarchical linear models (HLMs). In these models, individuals were nested within pairs for the sole purpose of accounting for the correlated variance between individuals playing in dyads, which was the case for two of three of the experimental conditions (i.e., competitive and collaborative play). The main intention of our analyses, however, was to draw conclusions at the level of the individual, not the pairs level, so our report chiefly focuses on individual-level effects.

Across all analyses, mode of play was dummy coded with competitive play and collaborative play entered into the models, and individual play as the reference group. All analyses were run using HLM Version 7 (Raudenbush, Bryk, \& Congdon, 2011). No gender or grade-level differences were found for the dependent variables; therefore, gender and grade level are not considered in further analyses.

\section{Game Performance}

Two indicators of game performance were analyzed. In our first analysis, we examined the effect of mode of play (individual vs. competitive vs. collaborative) on the number of problems solved in the posttest of game play. We ran an HLM with number of problems solved as the dependent variable, the two mode of play 


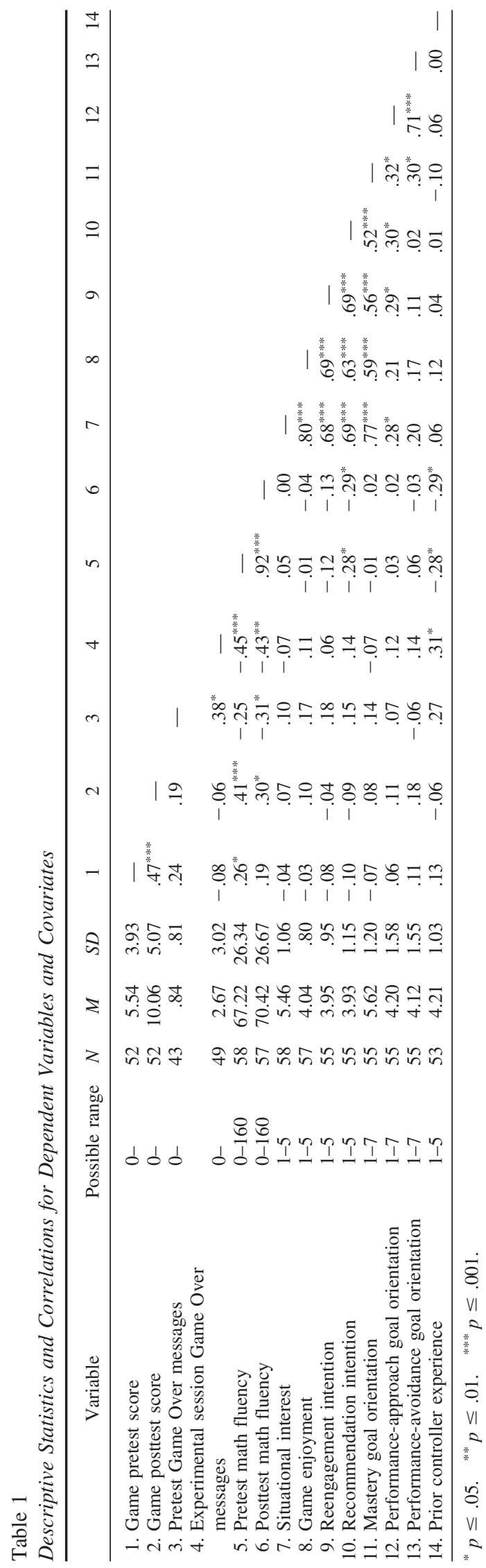

condition dummy variables, and two covariates: The number of pretest play problems solved served as a baseline of game ability, and the degree of players' experience with video game controllers served as a baseline for previous experience with controller-based video games. The equations took the following forms:

Level $1: Y_{i j}$ (posttest score $)=\beta_{0 j}+\beta_{1 j}$ (competition)

$+\beta_{2 j}($ collaboration $)+\beta_{3 j}$ (pretest score $)$

$+\beta_{4 j}($ controller experience $)+r_{i j}$.

Level 2: $\beta_{0 j}=\gamma_{00}+u_{0 j}, \beta_{1 j}=\gamma_{10}, \beta_{2 j}=\gamma_{20}, \beta_{3 j}=\gamma_{30}, \beta_{4 j}=\gamma_{40}$.

Results showed a fixed effect for the competitive condition ( $p=$ $.02)$, such that players in that condition performed significantly better than those in the individual condition (see Table 2 for parameter estimates and Figure 2 for a graphical depiction). No effect was found for the collaborative condition, however. An additional fixed effect was yielded for the pretest performance $(p<.001)$, suggesting that higher pretest scores were predictive of better performance in the posttest. A follow-up analysis comparing competitive and collaborative play suggested that there was no difference in posttest scores between the conditions $(p=.14)$.

Furthermore, there was a significant random effect suggesting that posttest scores varied between pairs, $\chi^{2}(38)=65.97, p=$ .004 . The intraclass correlation coefficient $(\mathrm{ICC}=.40)$ suggested that $40 \%$ of the variance in posttest scores could be explained by the variability between pairs, whereas $60 \%$ could be explained by the variability between players.

Our second analysis of game performance examined the number of times players received "Game Over" messages in the experimental play session, with higher numbers indicating poorer performance. In order to examine the effect mode of play had on problem-solving strategy use, we ran an HLM with number of "Game Over" messages received as the dependent variable. Dummy-coded variables for the mode-of-play conditions were included in the model along with pretest number of "Game Over" messages and prior experience with video game controllers as covariates. The equations took the following forms:

Level $1: Y_{i j}($ game over messages $)=\beta_{0 j}+\beta_{l j}$ (competition)

$$
\begin{aligned}
+\beta_{2 j}(\text { collaboration })+ & \beta_{3 j}(\text { pretest game over messages }) \\
& +\beta_{4 j}(\text { controller experience })+r_{i j} .
\end{aligned}
$$

Table 2

Estimates for Game Performance: Number of Correct Solutions During the Posttest

\begin{tabular}{lcc}
\hline \multicolumn{1}{c}{ Fixed effects } & Coefficient & $S E$ \\
\hline Intercept & $6.61^{* * *}$ & 2.52 \\
Competitive play & $4.20^{* *}$ & 1.61 \\
Collaborative play & 1.81 & 1.45 \\
Pretest problems solved & $.63^{* * * *}$ & .12 \\
Prior controller experience & -.45 & .47 \\
Random effects & & $\underline{\text { Variance }}$ \\
Pairs intercept & & $8.13^{* *}$ \\
\hline
\end{tabular}

${ }^{*} p \leq .05 .{ }^{* * *} p \leq .01 .{ }^{* * * *} p \leq .001$. 


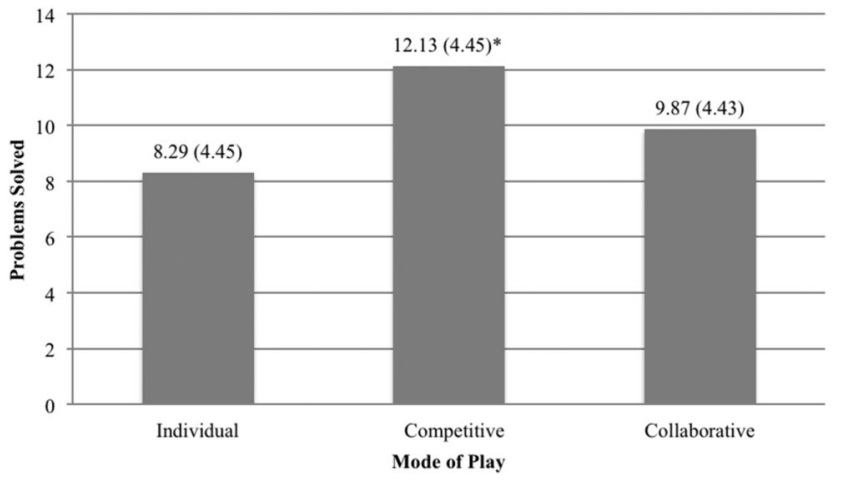

Figure 2. Adjusted means for number of problems solved in the posttest game play by condition. Values atop each bar represent means (and standard deviations). $P$ value reflects comparison with the individual play condition. ${ }^{*} p \leq .05$.

Level 2: $\beta_{0 j}=\gamma_{00}+u_{0 j}, \beta_{1 j}=\gamma_{10}, \beta_{2 j}=\gamma_{20}, \beta_{3 j}=\gamma_{30}, \beta_{4 j}=\gamma_{40}$.

The analysis yielded a statistically significant fixed main effect for collaborative play $(p=.004)$, suggesting that players in that condition had a higher rate of inefficient problem-solving strategy use than those in the individual play condition. No such effect was found for the competitive condition in relation to the individual play condition (see Table 3 for parameter estimates and Figure 3 for a graphical depiction). A follow-up analysis comparing the competitive and collaborative conditions suggested that there was no difference in the receipt of "Game Over" messages between the groups $(p=.11)$.

Furthermore, there was a significant random effect, $\chi^{2}(31)=$ $817.87, p<.001$, suggesting that the number of "Game Over" messages received varied between pairs. The ICC (ICC $=.96$ ) suggested that $96 \%$ of the variance in "Game Over" messages received was attributable to variability between pairs, whereas only $4 \%$ was attributable to variability between individual players.

\section{Achievement Goal Orientations}

Our next set of analyses examined the effect mode of play had on participants' adoption of achievement goal orientations during game play. In each of the three analyses, the achievement goal orientation score was entered as the dependent variable in an HLM

Table 3

Estimates for Game Performance: Number of "Game Over" Messages Received During the Experimental Trial

\begin{tabular}{lcc}
\hline \multicolumn{1}{c}{ Fixed effects } & Coefficient & $S E$ \\
\hline Intercept & .76 & .59 \\
Competitive play & 1.35 & .87 \\
Collaborative play & $3.53^{* *}$ & 1.09 \\
Pretest "Game Over" messages & .40 & .23 \\
Prior controller experience & -.02 & .12 \\
Random effects & & $\underline{\text { Variance }}$ \\
Pairs intercept & & $6.13^{* * *}$ \\
\hline
\end{tabular}

${ }^{* * *} p \leq .01 .{ }^{* * *} p \leq .001$.

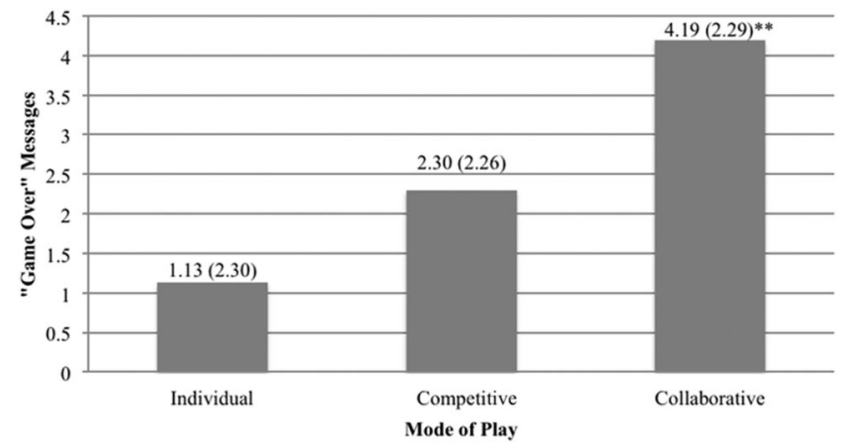

Figure 3. Adjusted means for number of "Game Over" messages received in the experimental play session by condition. Values atop each bar represent means (and standard deviations). $P$ value reflects comparison with the individual play condition. ${ }^{* *} p \leq .01$.

along with mode-of-play condition dummy codes as predictors. The equations took the following forms:

Level $1: Y_{i j}($ goal orientation $)=\beta_{0 j}+\beta_{1 j}($ competition $)$

$$
+\beta_{2 j} \text { (collaboration) }+r_{i j} \text {. }
$$

Level $2: \beta_{0 j}=\gamma_{00}+u_{0 j}, \beta_{1 j}=\gamma_{10}, \beta_{2 j}=\gamma_{20}$.

The analysis for mastery goal orientation scores yielded significant fixed main effects for both competitive $(p=.01)$ and collaborative ( $p=.04$ ) conditions, suggesting that both conditions invoked a stronger mastery goal orientation than did playing the game individually (see Figure 4 for a graphical depiction). A follow-up analysis, however, showed that mastery goal orientation strength did not differ between the competitive and collaborative groups $(p=.28)$. Furthermore, there was no significant random effect, $\chi^{2}(38)=38.19, p=.46$, suggesting that the strength of mastery goal orientations was not attributable to the variability between pairs.

For the performance-approach $\left(M_{\text {Ind }}=3.99, S D_{\text {Ind }}=1.32\right.$; $\left.M_{\text {Comp }}=4.67, S D_{\text {Comp }}=1.81 ; M_{\text {Coll }}=3.99, S D_{\text {Coll }}=1.55\right)$ and performance-avoidance analyses $\left(M_{\text {Ind }}=3.94, S D_{\text {Ind }}=1.47\right.$; $\left.M_{\mathrm{Comp}}=4.32, S D_{\mathrm{Comp}}=1.77 ; M_{\mathrm{Coll}}=4.09, S D_{\mathrm{Coll}}=1.49\right)$, no

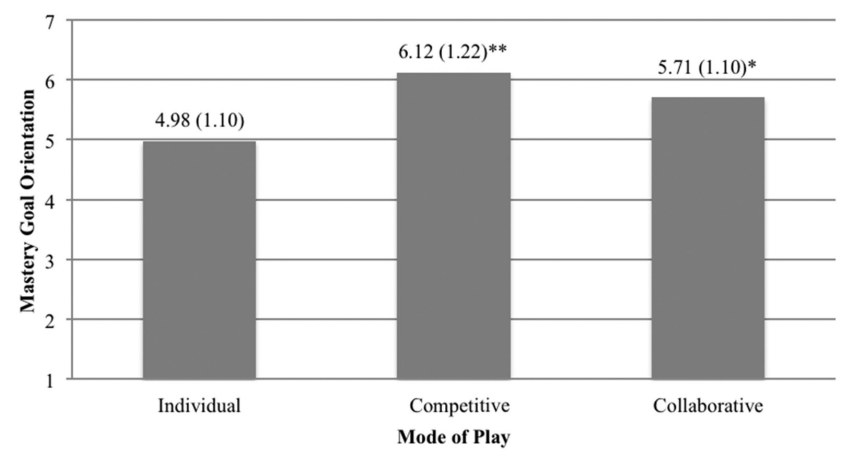

Figure 4. Mean adoption of mastery goal orientation by condition. Values atop each bar represent means (and standard deviations). $P$ value reflects comparison with the individual play condition. ${ }^{*} p \leq .05$. ${ }^{* *} p \leq$ .01 . 
significant effects were found. See Tables 4, 5, and 6 for parameter estimates for the three goal orientation models.

\section{Situational Interest}

Our next analysis examined the extent to which mode of play invoked situational interest in players during game play. Situational interest scores were entered in an HLM as the dependent variable along with the two mode-of-play condition dummy variables as predictors. The equations took the following forms:

Level $1: Y_{i j}($ situational interest $)=\beta_{0 j}+\beta_{1 j}($ competition $)$

$$
+\beta_{2 j} \text { (collaboration) }+r_{i j} \text {. }
$$

Level $2: \beta_{0 j}=\gamma_{00}+u_{0 j}, \beta_{1 j}=\gamma_{10}, \beta_{2 j}=\gamma_{20}$.

The analysis yielded statistically significant fixed main effects for both competitive $(p=.04)$ and collaborative play conditions ( $p=.01$; see Table 7 for parameter estimates and Figure 5 for a graphical depiction). These results suggest that playing in either competition or collaboration with another player made the game more exciting and personally relevant, as measured by the Situational Interest scale, than when playing it alone. A follow-up analysis comparing competitive and collaborative modes showed that they did not differ with respect to situational interest $(p=.59)$. Furthermore, no random effect was yielded, $\chi^{2}(40)=44.35, p=$ .29 , demonstrating that the variance in situational interest was not explained by the variability between pairs.

\section{Enjoyment}

We next examined the effect of mode of play on players' enjoyment of the game. Enjoyment scores were entered into the HLM as the dependent variable along with the dummy variables reflecting the mode-of-play conditions as predictors. The equations took the following forms:

Level $1: Y_{i j}($ enjoyment $)=\beta_{0 j}+\beta_{1 j}($ competition $)$

$$
+\beta_{2 j}(\text { collaboration })+r_{i j}
$$

Level $2: \beta_{0 j}=\gamma_{00}+u_{0 j}, \beta_{1 j}=\gamma_{10}, \beta_{2 j}=\gamma_{20}$.

The analysis yielded statistically significant fixed main effects of competitive $(p=.03)$ and collaborative $(p<.001)$ play on game enjoyment as compared with the individual play condition. These results suggest that playing the game alone was significantly less enjoyable than playing it either competitively or collaboratively (Table 8 lists the parameter estimates for the model, and

Table 4

Estimates for Mastery Goal Orientation

\begin{tabular}{lcc}
\hline \multicolumn{1}{c}{ Fixed effects } & Coefficient & $S E$ \\
\hline Intercept & $4.98^{* * * *}$ & .27 \\
Competitive play & $1.14^{* * *}$ & .40 \\
Collaborative play & $.74^{*}$ & .33 \\
Random effects & & $\underline{\text { Variance }}$ \\
\hline Pairs intercept & & .01 \\
\hline
\end{tabular}

${ }^{*} p \leq .05 . \quad{ }^{* *} p \leq .01 .{ }^{* * *} p \leq .001$.
Table 5

Estimates for Performance-Approach Goal Orientation

\begin{tabular}{lcc}
\hline \multicolumn{1}{c}{ Fixed effects } & Coefficient & $S E$ \\
\hline Intercept & $3.99^{* * * *}$ & .32 \\
Competitive play & .61 & .51 \\
Collaborative play & .04 & .51 \\
Random effects & & $\underline{\text { Variance }}$ \\
Pairs intercept & & .58 \\
\hline$* * * * 0.001$ & &
\end{tabular}

**** $p \leq .001$.

Figure 6 provides a graphical depiction). A follow-up analysis comparing the competitive and collaborative groups demonstrated that they did not differ with regard to their enjoyment of the game $(p=.38)$.

Finally, there was a significant random effect suggesting that enjoyment of the game varied between pairs, $\chi^{2}(40)=68.60, p=$ .003 . The ICC $(\mathrm{ICC}=.36)$ suggested that $36 \%$ of the variance in game enjoyment was explained by the variability between pairs, whereas $64 \%$ was explained by the variability between individual players.

\section{Future Game Intentions}

Two indicators of players' future intentions with regard to the game were examined. The first analysis examined the reported likelihood participants would play the game again. Reengagement intentions were entered into the hierarchical model as the dependent variable along with mode-of-play condition dummy codes. The equations took the following forms:

Level $1: Y_{i j}($ reengagement intentions $)=\beta_{0 j}+\beta_{1 j}($ competition $)$

$$
+\beta_{2 j} \text { (collaboration) }+r_{i j} \text {. }
$$

Level 2: $\beta_{0 j}=\gamma_{00}+u_{0 j}, \beta_{1 j}=\gamma_{10}, \beta_{2 j}=\gamma_{20}$.

The analysis resulted in a statistically significant fixed main effect of the collaborative condition $(p=.03)$, such that players in that condition reported a higher likelihood of playing the game again than those who played the game individually. No such effect was found for the competitive condition, however. Those participants' intentions to reengage in the game were no different than those in the individual play group. See Table 9 for the model parameter estimates and Figure 7 for a graphical depiction. A follow-up analysis further suggested that intentions to play the game again were no different for those in the competitive and collaborative play conditions ( $p=.57$ ). Furthermore, there was no

Table 6

Estimates for Performance-Avoidance Goal Orientation

\begin{tabular}{lcc}
\hline \multicolumn{1}{c}{ Fixed effects } & Coefficient & $S E$ \\
\hline Intercept & $3.94^{* * * * *}$ & .36 \\
Competitive play & .37 & .59 \\
Collaborative play & .15 & .45 \\
Random effects & & $\underline{\text { Variance }}$ \\
Pairs intercept & & .29 \\
**** $p \leq .001$. & &
\end{tabular}


Table 7

Estimates for Situational Interest

\begin{tabular}{lcc}
\hline \multicolumn{1}{c}{ Fixed effects } & Coefficient & $S E$ \\
\hline Intercept & $4.92^{* * * *}$ & .24 \\
Competitive play & $.74^{*}$ & .33 \\
Collaborative play & $.90^{* *}$ & .31 \\
Random effects & & Variance \\
Pairs intercept & & .05 \\
\hline
\end{tabular}

${ }^{*} p \leq .05 .{ }^{* *} p \leq .01 .{ }^{* * *} p \leq .001$.

significant random effect, $\chi^{2}(39)=36.93, p>.50$, suggesting that the variance in intentions to reengage in the game was not due to variability between pairs.

The second future intention examined was players' intention to recommend the game to a friend or teacher. Therefore, recommendation intentions were added to the hierarchical model as a dependent variable along with the mode-of-play condition dummy variables. The equations took the following forms:

Level $1: Y_{i j}($ recommendation intentions $)=\beta_{0 j}$

$$
+\beta_{1 j}(\text { competition })+\beta_{2 j}(\text { collaboration })+r_{i j} \text {. }
$$

Level $2: \beta_{0 j}=\gamma_{00}+u_{0 j}, \beta_{1 j}=\gamma_{10}, \beta_{2 j}=\gamma_{20}$.

The analysis yielded a statistically significant fixed effect for the collaborative condition ( $p=.01$ ), but not the competitive condition. These results suggest that playing the game collaboratively led participants to report a stronger intention to recommend the game to someone else than those who played the game individually (see Table 10 for parameter estimates and Figure 8 for a graphical depiction). A follow-up analysis comparing the competitive and collaborative conditions yielded a null result $(p=.43)$, demonstrating that intentions to recommend the game did not differ between the two groups. Furthermore, there was no significant random effect, $\chi^{2}(39)=40.24, p=.42$, suggesting that recommendation intentions did not vary between pairs.

\section{Math Fluency}

Before investigating the effect of game play condition on math fluency, we first examined whether there was an overall change

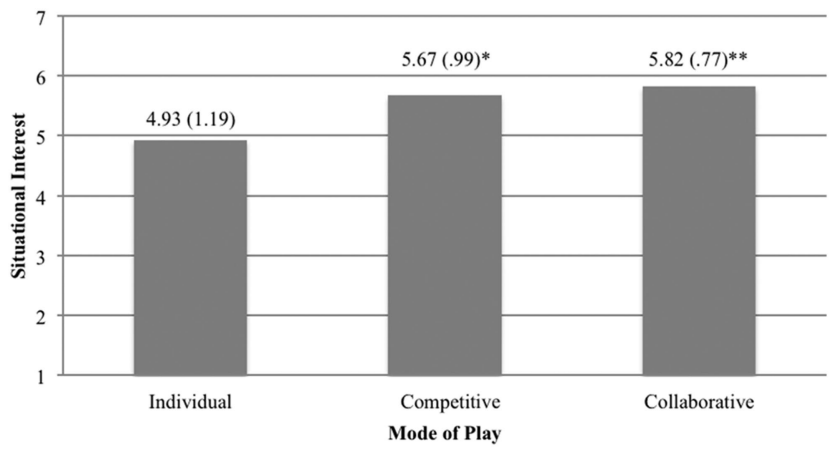

Figure 5. Mean situational interest scores by condition. Values atop each bar represent means (and standard deviations). $P$ value reflects comparison with the individual play condition. ${ }^{*} p \leq .05$. ${ }^{* *} p \leq .01$.
Table 8

Estimates for Game Enjoyment

\begin{tabular}{lcc}
\hline \multicolumn{1}{c}{ Fixed effects } & Coefficient & $S E$ \\
\hline Intercept & $7.04^{* * * *}$ & .37 \\
Competitive play & $1.33^{*}$ & .53 \\
Collaborative play & $1.82^{* * *}$ & .44 \\
Random effects & & $\underline{\text { Variance }}$ \\
Pairs intercept & & $.76^{* *}$ \\
\hline
\end{tabular}

${ }^{*} p \leq .05 .{ }^{* *} p \leq .01 .{ }^{* * *} p \leq .001$.

from pre- to posttest fluency scores (see Table 11). A paired $t$ test comparing pre- and posttest fluency scores was conducted; however, one participant did not complete the posttest and was thus omitted from the analysis. Results suggested that posttest fluency scores $(M=70.42, S D=26.67)$ were statistically significantly higher than pretest scores $(M=66.86, S D=26.42), t(56)=$ $-2.59, p=.01$. Therefore, players increased their math fluency from pre- to posttest.

Next, we analyzed posttest math fluency scores to investigate the effect of condition. Dummy-coded modes of play were entered into the model along with pretest fluency scores as a covariate. The equations took the following forms:

Level $1: Y_{i j}$ (posttest fluency scores $)=\beta_{0 j}+\beta_{1 j}$ (competition)

$$
\left.+\beta_{2 j}(\text { collaboration })+\beta_{3 j} \text { (pretest fluency scores }\right)+r_{i j} \text {. }
$$

Level $2: \beta_{0 j}=\gamma_{00}+u_{0 j}, \beta_{1 j}=\gamma_{10}, \beta_{2 j}=\gamma_{20}, \beta_{3 j}=\gamma_{30}$.

Although the effect of pretest fluency scores was found to be significant $(p<.001)$, indicating a positive relation with posttest scores, the analysis indicated no effect of collaborative play or competitive play on posttest math fluency scores. The null result suggests that there were no differences in fluency scores between the individual $(M=65.63, S D=15.21)$, competitive $(M=78.68$, $S D=36.47)$, and collaborative $(M=66.77, S D=22.30)$ game play conditions. The effect of the grouping variable, pairs, on posttest math fluency scores was found to be not statistically significant. This indicates that none of the variance in posttest math fluency scores is attributable to the pairings after accounting for variability from pretest fluency scores. Furthermore, there was

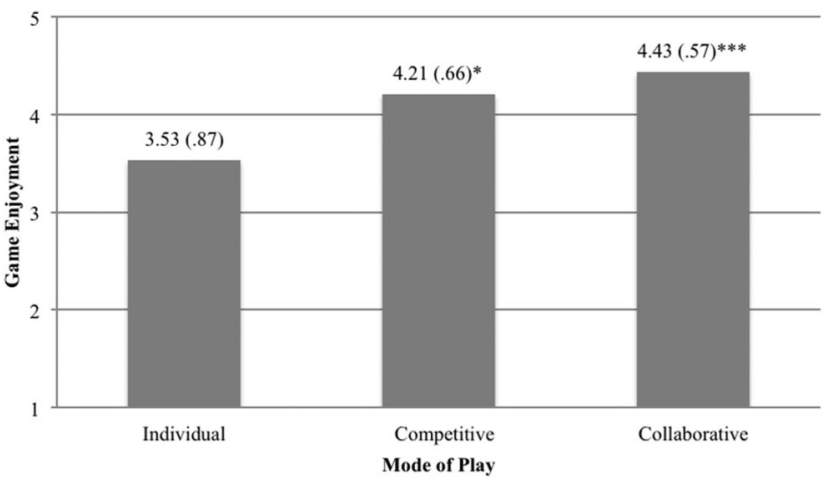

Figure 6. Mean game enjoyment scores by condition. Values atop each bar represent means (and standard deviations). $P$ value reflects comparison with the individual play condition. ${ }^{*} p \leq .05$. ${ }^{* * *} p \leq .001$. 
Table 9

Estimates for Future Game Intentions: Reengagement

\begin{tabular}{lcc}
\hline \multicolumn{1}{c}{ Fixed effects } & Coefficient & $S E$ \\
\hline Intercept & $3.58^{* * * *}$ & .22 \\
Competitive play & .48 & .32 \\
Collaborative play & $.63^{*}$ & .26 \\
Random effects & & $\underline{\text { Variance }}$ \\
Pairs intercept & & .00 \\
\hline
\end{tabular}

${ }^{*} p \leq .05 . * * * p \leq .001$.

no significant random effect, $\chi^{2}(39)=33.01, p>.50$, suggesting that math fluency did not vary between pairs.

\section{Discussion}

The goal of the present research was to investigate the learning, performance, and motivational outcomes associated with playing an educational math game either competitively or collaboratively as compared with individually. With a few exceptions, our predictions were confirmed.

Two analyses were conducted to assess the affect of mode of play on within-game learning and performance. The first analysis examined the number of problems solved in the posttest, which showed that, in comparison to individual play, performance was better for competitive, but not collaborative play. Playing competitively may have aided in the development of arithmetic skills such that players were able to solve more problems during the withingame posttest. Our second analysis examined the efficiency of problem-solving strategies used by learners during the experimental session, operationalized as the number of "Game Over" screens received by the player, which found that collaborative play resulted in worse performance than individual play. There was no difference, however, in performance between competitive and individual modes of play.

There may be different explanations for these results. One possibility is that our findings may be specific to the game used in the present study. Indeed, collaboration has been shown to be beneficial for motivation and learning under numerous circumstances (e.g., Deutsch \& Krauss, 1960; Hänze \& Berger, 2007; Nichols, 1996; Nichols \& Miller, 1994; Sharan \& Shaulov, 1990;

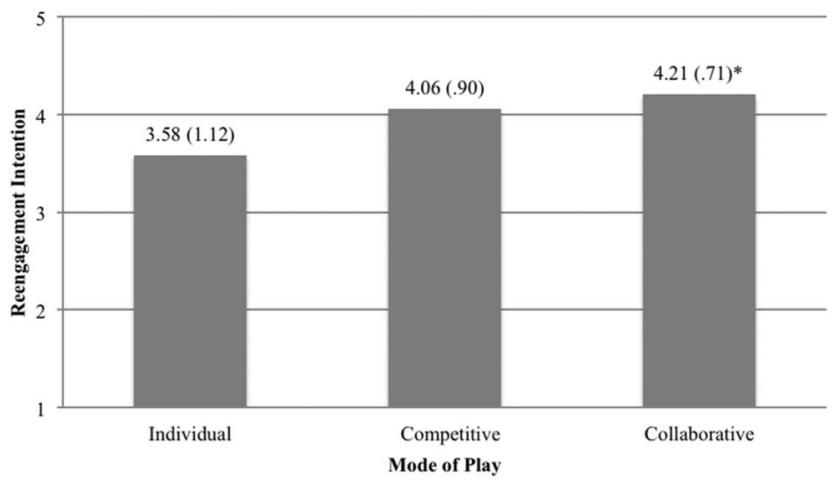

Figure 7. Mean intent to play game again by condition. Values atop each bar represent means (and standard deviations). $P$ value reflects comparison with the individual play condition. ${ }^{*} p \leq .05$.
Table 10

Estimates for Future Game Intentions: Recommendation

\begin{tabular}{lcc}
\hline \multicolumn{1}{c}{ Fixed effects } & Coefficient & $S E$ \\
\hline Intercept & $3.42^{* * * *}$ & .27 \\
Competitive play & .64 & .39 \\
Collaborative play & $.89^{* * *}$ & .31 \\
Random effects & & $\underline{\text { Variance }}$ \\
Pairs intercept & & .00 \\
${ }^{* * *} p \leq .01 .^{* * * *} p \leq .001$. & &
\end{tabular}

Slavin, 1988). FactorReactor, however, requires players in the collaborative mode to communicate with each other, negotiating which strategy to select, and who will execute which move. For the automation of arithmetic fluency, these particular tasks may be best suited for modes in which players are in sole control of their game space, as they were in the individual and competitive modes of the present study. This is in line with findings by Mullins et al. (2011), who found that the mutual elaborations and explanations were beneficial for conceptual knowledge, but not for skill development. Another possible explanation is that the relatively short game play penalized players for their collaborative meaningmaking and exploration, which was reflected in fewer problems solved, and more inefficient strategies explored, than individual play. In a longer game play, this initial exploration may have eventually resulted in better performance than individual or competitive play, which should be investigated in future research.

It should also be noted that it is uncertain whether within-game learning occurred because players in the competitive condition had improved their math fluency or whether there were other explanations. For example, competitive players may have increased their fluency of the game mechanics relative to those in other modes of play, or honed their strategies more effectively. In other words, it is possible that they improved their game-playing skills rather than their arithmetic skills. Future research will need to investigate these possible sources of increased fluency.

Another set of analyses examined out-of-game learning, which was assessed using timed paper-and-pencil tests before and after participants played the game. It was found that players' math fluency scores had improved overall. Without additional data,

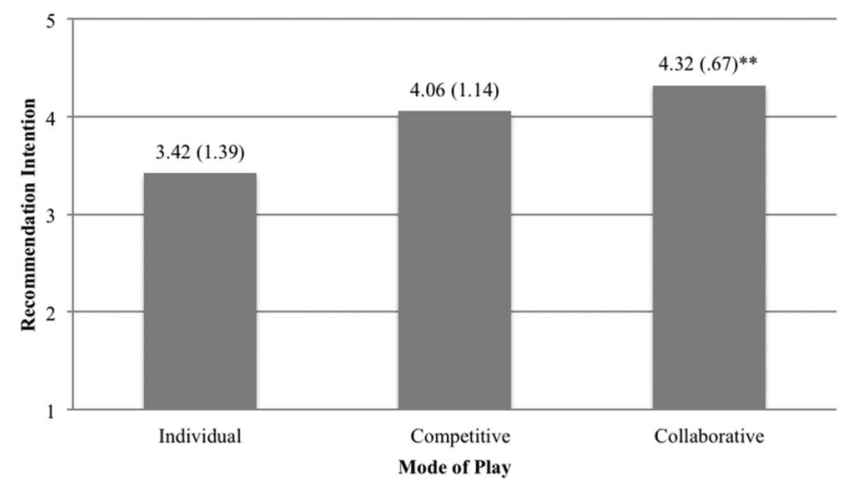

Figure 8. Mean intent to recommend game by condition. Values atop each bar represent means (and standard deviations). $P$ value reflects comparison with the individual play condition. ${ }^{* *} p \leq .01$. 
Table 11

Estimates for Math Fluency

\begin{tabular}{lcc}
\hline \multicolumn{1}{c}{ Fixed effects } & Coefficient & $S E$ \\
\hline Intercept & 6.14 & 4.31 \\
Competitive play & -2.59 & 3.39 \\
Collaborative play & -.39 & 3.25 \\
Pretest problems solved & $.98^{* * * *}$ & .06 \\
Random effects & & Variance \\
Pairs intercept & & .17 \\
\hline
\end{tabular}

*** $p \leq .001$.

however, we cannot necessarily claim that the increase in scores was due to playing the game rather than reflecting a test-taking effect. Contrary to our predictions, a second analysis showed that posttest scores did not vary by condition. Although it is possible that the skills acquired during game play do not transfer to outof-game measures of learning, the relatively short duration of game play may have not been sufficient for the transfer to occur.

A series of analyses were also conducted to examine the effect of mode of play on multiple indicators of motivation. In comparison to individual play, competitive and collaborative play resulted in the strongest mastery goal orientation, which is associated with highly adaptive patterns of motivation and learning (Ames, 1992; Midgley et al., 2001). This finding suggests that these modes of play may impact students' learning-related goals to focus more on learning the subject matter, improving, and finding the most optimal strategies, and less on normative comparisons with other students or validating their abilities. This notion is further supported by the fact that we found that the competitive and collaborative modes of play did not differ from individual play in their invocation of performance-approach and performance-avoidance goal orientations. This null finding may have stemmed from the way in which participants experienced the competitive mode. Although performance goals are concerned with outperforming others, it is in the service of demonstrating normative ability (e.g., Grant \& Dweck, 2003; Urdan \& Mestas, 2006). Indeed, performance goals and competition are different constructs. Playing in competition with another student may not be sufficient to invoke concerns about normative ability. If a student were to play against all of his or her classmates and their scores were made available to each other, however, a concern for normative performance may be elicited, along with a performance goal. In other words, although competition may play a role in the invocation of performance goals, such that there exists a desire to outperform others, our data suggest that the way in which competition was operationalized in FactorReactor was not sufficient to invoke performance goal orientations. Given the properties of the game we used, our results suggest that in the context of a learning game, competition with only one other player, rather than all other classmates, may be an effective means of invoking a mastery goal orientation without the negative outcomes associated with the invocation of performance goal orientations.

Our results also demonstrated that competitive and collaborative play increased situational interest and game enjoyment in relation to individual play. That these constructs were augmented has particularly important implications for the use of these modes of play in educational games. First, students are more likely to engage in a task they perceive to be enjoyable (Salen \& Zimmerman, 2003), thereby increasing their exposure to the educational content. Second, the invocation of situational interest suggests that the effect of the game reaches beyond mere enjoyment. Relative to the individual play condition, players in the competitive and collaborative conditions experienced the game as personally involving and that the content of the game was valuable and personally relevant. This increase in situational interest lays a foundation on which a more internalized and enduring interest, individual interest, is built.

Additionally, collaborative play increased participants' intention to play the game again and to recommend the game to another. This supports the notion that games not only engage students in particular learning activities and content but also increases the likelihood of reengagement over time, in and out of classroom (Gee, 2007; Squire, 2003). It also suggests that they may foster the development of a more internalized individual interest that intrinsically guides students' future learning endeavors, both alone and assisted by an instructor (Bergin, 1999; Deci, Vallerand, Pelletier, \& Ryan, 1991).

It should be noted that our indicators of motivation were generally assessed in terms of the game itself. Therefore, it is possible that our results reflect motivational responses to the game rather than arithmetic. The intention of educational games, however, is to provide a context that engages learners and motivates them to reengage over time. Furthermore, the effectiveness of these games is attributable, in part, to their ability to reengage learners. For example, a student who enjoys a math game may play it frequently, resulting in increased exposure to and practice with mathematical operations. Even so, a number of the items used to assess motivation referred specifically to the learning content of the game, as with our assessment of situational interest, which likewise resulted in our predicted effects.

Taken together, our results suggest that there are benefits and costs associated with particular modes of play. Although the competitive and collaborative modes elicited the strongest motivation and interest, and increased the degree to which mastery goal orientations were adopted, the collaborative condition resulted in the highest frequency of inefficient strategy use, yet led to more positive attitudes toward the game. More specifically, participants in the collaborative condition had to restart the most levels, suggesting that their collaborations were inefficient and error-prone, and led to the use of poor strategies as compared to those in the individual mode. Yet, collaborative play also led to greater intentions to play the game again, suggesting that, over time, this negative effect could be resolved.

\section{Limitations and Future Research}

As is the case for all empirical studies, there are some limitations to the generalizability of our findings. Most importantly, the results of this study cannot be readily generalized to all educational games. The game used in this research, FactorReactor, was designed for the practice and automation of arithmetic skills to increase fluency in middle-school students. There are many genres of games with features that differ significantly from this game, such as role-playing games, adventure games, augmented reality games, or first-person shooters. Because of the corresponding design differences, a different effect of mode of play might be 
expected for other game genres. For example, we found collaborative play to increase the rate of adoption of inefficient and error-prone strategies during the game. We would not, however, suggest that collaboration is detrimental to performance in general. The characteristics of this particular game may not have been ideal for collaborative play within a 15 -min period, which may have been alleviated by the fact that we chose, for the reasons outlined above, to keep instruction on how to collaborate to a minimum. Future research will need to investigate whether our findings can be replicated with games with similar objectives, but from other game genres. Future work should also examine the effects of other design factors, and should investigate whether the effects found in the present study are different for games that cover different kinds of knowledge, for example, whether collaborative game play would result in better learning of conceptual knowledge, as suggested by Mullins et al. (2011). We are also interested in conducting further research to explore the learning processes in individual versus collaborative and competitive game modes by collecting process data such as biometrics and eye tracking (Aleven, Rau, \& Rummel, 2012).

\section{Conclusion}

The results of this study, which provide initial evidence for the effect of social context in game-based development of arithmetic fluency, have important theoretical and practical implications.

On the theoretical side, we demonstrated that although only the competitive mode of play increased within-game learning, both competitive and collaborative modes of play increased situational interest, enjoyment, and the adoption of a mastery goal orientation, compared with individual play. These results are in line with previous research in computer-supported learning of mathematics that showed that benefits of collaboration were only found for conceptual knowledge, but not found for skills acquisition (Mullins et al., 2011). Our research extended these findings by also considering the impact of a form of competition that has the benefits of increased performance while still invoking a mastery goal orientation rather than a performance goal orientation. It is especially interesting that although resulting in inefficient use of problem-solving strategies and error-prone game play, collaborative play was associated with greater enjoyment, situational interest, and intention of reengagement than individual play. These results fit within a framework of learning with media that recognizes the importance of social context and related affective variables in addition to cognitive ones (Moreno \& Mayer, 2007).

On the practical side, this research provides empirical support for the potential of educational games as effective learning environments that provide incentives for students to play repeatedly over time. Our results demonstrate that game designers need to earnestly consider the differential effects of competitive and collaborative modes of a game in skill fluency development. Although both modes of social play increase situational interest and future intentions to play, only the competitive mode resulted in increases in game performance compared with individual play, whereas collaborative play resulted in the adoption of less efficient problem-solving strategies. This research also highlights that many of the outcomes of learning with gamelike environments are of an affective nature and that such affective outcomes of motivation and interest have to be considered in addition to the cognitive learning outcomes of a game.

In summary, the research reported in this study provides empirical support for a social context design pattern that emphasizes competitive modes of play over collaborative and individual play for games aimed at developing arithmetic skill fluency and adopting of a mastery goal orientation, as well as increasing situational interest and enjoyment.

\section{References}

Aleven, V., Rau, M., \& Rummel, N. (2012). Planned use of eye movement data to explore complementary strengths of individual and collaborative learning. Proceedings of the DUET 2012 - Dual Eye-Tracking in CSCW Meeting. Retrieved from http://dualeyetracking.org/duet2012/Program_ files/DUET2012_1.pdf

Alexander, C., Ishikawa, S., \& Silverstein, M. (1977). A pattern language: Towns, buildings, construction (Vol. 2). New York, NY: Oxford University Press.

Ames, C. (1984). Achievement attributions and self-instructions under competitive and individualistic goal structures. Journal of Educational Psychology, 76, 478-487. doi:10.1037/0022-0663.76.3.478

Ames, C. (1992). Classrooms: Goals, structures, and student motivation. Journal of Educational Psychology, 84, 261-271. doi:10.1037/00220663.84.3.261

Ames, C., \& Archer, J. (1988). Achievement goals in the classroom: Students' learning strategies and motivation processes. Journal of Educational Psychology, 80, 260-267. doi:10.1037/0022-0663.80.3.260

Ames, C., \& Felker, D. (1979). An examination of children's attributions and achievement-related evaluations in competitive, cooperative, and individualistic reward structures. Journal of Educational Psychology, 71, 413-420. doi:10.1037/0022-0663.71.4.413

Barab, S., Ingram-Goble, A., \& Warren, S. (2008). Conceptual play spaces. In R. E. Ferdig (Ed.), Handbook of research on effective electronic gaming in education (pp. 989-1009). New York, NY: IGI Global.

Barab, S. A., Thomas, M., Dodge, T., Carteaux, R., \& Tuzun, H. (2005). Making learning fun: Quest Atlantis, a game without guns. Educational Technology Research and Development, 53, 86-107. doi:10.1007/ BF02504859

Berg, K. F. (1994). Scripted cooperation in high school mathematics: Peer interaction and achievement. Paper presented at the annual meeting of the American Educational Research Association, New Orleans, LA.

Bergin, D. (1999). Influences on classroom interest. Educational Psychologist, 34, 87-98. doi:10.1207/s15326985ep3402_2

Bloom, B. S. (Ed.). (1956). Taxonomy of educational objectives: Handbook I. Cognitive domain. New York, NY: McKay.

Chaudhuri, S., Kumar, R., Joshi, M., Terrell, E., Higgs, F., Aleven, V., \& Rosé, C. P. (2008). It's not easy being green: Supporting collaborative "green design" learning. In E. Aimeur \& B. Woolf (Eds.), Proceedings of the Ninth International Conference on Intelligent Tutoring Systems (pp. 807-809). Berlin, Germany: Springer-Verlag.

Church, M. A., Elliot, A. J., \& Gable, S. L. (2001). Perceptions of classroom environment, achievement goals, and achievement outcomes. Journal of Educational Psychology, 93, 43-54. doi:10.1037/0022-0663 .93 .1 .43

Cobb, P., Wood, T., \& Yackel, E. (1991). A constructivist approach to second-grade mathematics. In E. von Glasersfeld (Ed.), Constructivism in mathematics education (pp. 157-176). Dordrecht, the Netherlands: Kluwer.

Collins, A., \& Halverson, R. (2009). Rethinking education in the age of technology: The digital revolution and schooling in America. New York, NY: Teachers College.

Cury, F., Elliot, A. J., Da Fonseca, D., \& Moller, A. C. (2006). The Social-cognitive model of achievement motivation and the $2 \times 2$ 
achievement goal framework. Journal of Personality and Social Psychology, 90, 666-679. doi:10.1037/0022-3514.90.4.666

Deci, E. L., Vallerand, R. J., Pelletier, L. G., \& Ryan, R. M. (1991). Motivation and education: The self-determination perspective. Educational Psychologist, 26, 325-346.

Deutsch, M., \& Krauss, R. M. (1960). The effect of threat upon interpersonal bargaining. Journal of Abnormal and Social Psychology, 61, 181-189. doi:10.1037/h0042589

Dillenbourg, P. (1999). Introduction: What do you mean by "collaborative learning? In P. Dillenbourg (Ed.), Collaborative learning - cognitive and computational approaches (pp. 1-19). Amsterdam, the Netherlands: Pergamon.

Diziol, D., Rummel, N., Spada, H., \& McLaren, B. (2007). Promoting learning in mathematics: Script support for collaborative problem solving with the Cognitive Tutor Algebra. In C. A. Chinn, G. Erkens, \& S. Puntambekar (Eds.), Mice, minds and society: Proceedings of the Computer Supported Collaborative Learning (CSCL) Conference 2007 (Vol. 8, pp. 39-41). New Brunswick, NJ: International Society of the Learning Sciences.

Diziol, D., Walker, E., Rummel, N., \& Koedinger, K. R. (2010). Using intelligent tutor technology to implement adaptive support for student collaboration. Educational Psychology Review, 22, 89-102.

Dweck, C. S. (1986). Motivational processes affecting learning. American Psychologist, 41, 1040-1048. doi:10.1037/0003-066X.41.10.1040

Dweck, C. S., \& Leggett, E. L. (1988). A social-cognitive approach to motivation and personality. Psychological Review, 95, 256-273. doi: 10.1037/0033-295X.95.2.256

Elliot, A. J. (1999). Approach and avoidance motivation and achievement goals. Educational Psychologist, 34, 169-189. doi:10.1207/ s15326985ep3403_3

Elliot, A. J. (2005). A conceptual history of the achievement goal construct. In A. J. Elliot \& C. S. Dweck (Eds.), Handbook of competence and motivation (pp. 52-72). New York, NY: Guilford Publications.

Elliot, A. J., \& Mapes, R. R. (2005). Approach-avoidance motivation and self-concept evaluation. In A. Tesser, J. V. Wood, \& D. A. Stapel (Eds.), On building, defending and regulating the self: A psychological perspective (pp. 171-196). New York, NY: Psychology Press.

Elliot, A. J., \& McGregor, H. A. (1999). Test anxiety and the hierarchical model of approach and avoidance achievement motivation. Journal of Personality and Social Psychology, 76, 628-644. doi:10.1037/00223514.76.4.628

Elliot, A. J., \& McGregor, H. A. (2001). A $2 \times 2$ achievement goal framework. Journal of Personality and Social Psychology, 80, 501-519. doi:10.1037/0022-3514.80.3.501

Elliott, E. S., \& Dweck, C. S. (1988). Goals: An approach to motivation and achievement. Journal of Personality and Social Psychology, 54, 5-12. doi:10.1037/0022-3514.54.1.5

Fischer, F., Bruhn, J., Gräsel, C., \& Mandl, H. (2002). Fostering collaborative knowledge construction with visualization tools. Learning and Instruction, 12, 213-232.

Fu, F., Wu, Y., \& Ho, H. (2009). An investigation of coopetitive pedagogic design for knowledge creation in web-based learning. Computers \& Education, 53, 550-562. doi:10.1016/j.compedu.2009.01.004

Gee, J. P. (2003). What video games have to teach us about learning and literacy. New York, NY: Palgrave Macmillan. doi:10.1145/950566 .950595

Gee, J. P. (2007). Good video games + Good learning. New York, NY: Peter Lang.

Grant, H., \& Dweck, C. S. (2003). Clarifying achievement goals and their impact. Journal of Personality and Social Psychology, 85, 541-553. doi:10.1037/0022-3514.85.3.541

Hänze, M., \& Berger, R. (2007). Cooperative learning, motivational effects, and student characteristics: An experimental study comparing cooperative learning and direct instruction in 12th grade physics classes.
Learning and Instruction, 17, 29-41. doi:10.1016/j.learninstruc.2006.11 .004

Harackiewicz, J. M., Barron, K. E., Pintrich, P. R., Elliot, A. J., \& Thrash, T. M. (2002). Revision of achievement goal theory: Necessary and illuminating. Journal of Educational Psychology, 94, 638-645. doi: 10.1037/0022-0663.94.3.638

Harackiewicz, J. M., Barron, K. E., Tauer, J. M., Carter, S. M., \& Elliot, A. J. (2000). Short-term and long-term consequences of achievement goals: Predicting interest and performance over time. Journal of Educational Psychology, 92, 316-330. doi:10.1037/0022-0663.92.2.316

Hidi, S., \& Renninger, K. A. (2006). The Four-phase model of interest development. Educational Psychologist, 41, 111-127. doi:10.1207/ s15326985ep4102_4

Hron, A., \& Friedrich, H. F. (2003). A review of Web-based collaborative learning: Factors beyond technology. Journal of Computer Assisted Learning, 19, 70-79.

Hron, A., Hesse, F. W., Cress, U., \& Giovis, C. (2000). Implicit and explicit dialogue structuring in virtual learning groups. British Journal of Educational Psychology, 70, 53-64.

Johnson, D. W., Johnson, R. T., Maruyama, G., Nelson, D., \& Skon, L. (1981). Effects of cooperative, competitive, and individualistic goa structures on achievement: A meta analysis. Psychological Bulletin, 89, 47-62. doi:10.1037/0033-2909.89.1.47

Johnson, R. T., Johnson, D. W., \& Stanne, M. B. (1986). Comparison of computer-assisted cooperative, competitive, and individualistic learning. American Educational Research Journal, 23, 382-392.

Kafai, Y. (1995). Minds in play: Computer game design as a context for children's learning. Mahwah, NJ: Lawrence Erlbaum.

Karabenick, S. A. (2004). Perceived achievement goal structure and college student help seeking. Journal of Educational Psychology, 96, 569581. doi:10.1037/0022-0663.96.3.569

Ke, F., \& Grabowski, B. (2007). Gameplaying for maths learning: Cooperative or not? British Journal of Educational Technology, 38, 249-259. doi:10.1111/j.1467-8535.2006.00593.x

Kirschner, F., Paas, F., Kirschner, P. A., \& Janssen, J. (2011). Differential effects of problem-solving demands on individual and collaborative learning outcomes. Learning and Instruction, 21, 587-599. doi:10.1016/ j.learninstruc.2011.01.001

Lemaire, P., \& Siegler, R. S. (1995). Four aspects of strategic change: Contributions to children's learning of multiplication. Journal of Experimental Psychology: General, 124, 83-97. doi:10.1037/0096-3445.124 .1 .83

Light, P., \& Littleton, K. (1999). Social processes in children's learning. Cambridge, UK: Cambridge University Press.

Linnenbrink, E. A. (2005). The dilemma of performance-approach goals: The use of multiple goal contexts to promote students' motivation and learning. Journal of Educational Psychology, 97, 197-213. doi:10.1037/ 0022-0663.97.2.197

Linnenbrink-Garcia, L., Durik, A. M., Conley, A. M., Barron, K. E., Tauer, J. M., Karabenick, S. A., \& Harackiewicz, J. M. (2010). Measuring situational interest in academic domains. Educational and Psychological Measurement, 70, 647-671. doi:10.1177/0013164409355699

Lou, Y., Abrami, P. C., Spence, J. C., Poulsen, C., Chambers, B., \& d'Apollonia, S. (1996). Within-class grouping: A meta-analysis. Review of Educational Research, 66, 423-458.

Maehr, M. L., \& Zusho, A. (2009). Achievement goal theory: The past, present, and future. In K. R. Wentzel \& A. Wigfield (Eds.), Handbook of motivation at school (pp. 77-104). New York, NY: Routledge/Taylor \& Francis Group.

Mayo, M. J. (2007). Games for science and engineering education. Communications of the ACM, 50, 30-35. doi:10.1145/1272516.1272536

McGrew, K. S., \& Woodcock, R. W. (2001). Technical manual: Woodcock-Johnson III. Itasca, IL: Riverside. 
Meece, J. L., Anderman, E. M., \& Anderman, L. H. (2006). Classroom goal structures, student motivation, and academic achievement. Annиal Review of Psychology, 57, 487-503. doi:10.1146/annurev.psych.56 .091103 .070258

Meece, J. L., Blumenfeld, P. C., \& Hoyle, R. (1988). Students' goal orientations and cognitive engagement in classroom activities. Journal of Educational Psychology, 80, 514-523. doi:10.1037/0022-0663.80.4 .514

Mevarech, Z. R., Stern, D., \& Levita, I. (1987). To cooperate or not to cooperate in CAI: That is the question. Journal of Educational Research, $80,164-167$.

Middleton, M. J., \& Midgley, C. (1997). Avoiding the demonstration of lack of ability: An underexplored aspect of goal theory. Journal of Educational Psychology, 89, 710-718. doi:10.1037/0022-0663.89.4.710

Midgley, C., Kaplan, A., \& Middleton, M. (2001). Performance-approach goals: Good for what, for whom, under what circumstances, and at what cost? Journal of Educational Psychology, 93, 77-86. doi:10.1037/00220663.93.1.77

Midgley, C., Kaplan, A., Middleton, M., Maehr, M. L., Urdan, T., Hicks, L., . . Roeser, R. (1998). The development and validation of scales assessing students' achievement goal orientations. Contemporary Educational Psychology, 23, 113-131. doi:10.1006/ceps.1998.0965

Midgley, C., Maehr, M. L., Hruda, L. Z., Anderman, E., Anderman, L. H., Freeman, K. E., . . . Urdan, T. (2000). Manual for the Patterns of Adaptive Learning Scales (PALS). Ann Arbor: University of Michigan.

Moreno, R., \& Mayer, R. E. (2007). Interactive multimodal learning environments. Educational Psychology Review, 19, 309-326. doi: 10.1007/s10648-007-9047-2

Mullins, D., Rummel, N., \& Spada, H. (2011). Are two heads always better than one? Differential effects of collaboration on students' computersupported learning in mathematics. International Journal of ComputerSupported Collaborative Learning, 6, 421-443. doi:10.1007/s11412011-9122-Z

Nichols, J. D. (1996). The effects of cooperative learning on achievement and motivation in a high school geometry class. Contemporary Educational Psychology, 21, 467-476. doi:10.1006/ceps.1996.0031

Nichols, J. D., \& Miller, R. B. (1994). Cooperative learning and student motivation. Contemporary Educational Psychology, 19, 167-178. doi: 10.1006/ceps.1994.1015

O'Keefe, P. A., Ben-Eliyahu, A., \& Linnenbrink-Garcia, L. (2013). Shaping achievement goal orienations in a mastery-structured environment and concomitant changes in related contingencies of self-worth. Motivation \& Emotion, 37, 50-64. doi:10.1007/s11031-012-9293-6

Pekrun, R., Elliot, A. J., \& Maier, M. A. (2009). Achievement goals and achievement emotions: Testing a model of their joint relations with academic performance. Journal of Educational Psychology, 101, 115135. doi: $10.1037 / \mathrm{a} 0013383$

Piaget, J. (1932). The moral judgment of the child. Oxford, England: Harcourt, Brace.

Plass, J. L., Homer, B. D., Chang, Y. K., Frye, J., Kaczetow, W., Isbister, K., \& Perlin, K. (2013). Metrics to assess learning and measure learner variables in simulations and games. In M. S. El-Nasr, A. Drachen, \& A. Canossa (Eds.), Game analytics-maximizing the value of player data (pp. 697-729). New York, NY: Springer.

Plass, J. L., Homer, B. D., \& Hayward, E. (2009). Design factors for educationally effective animations and simulations. Journal of Computing in Higher Education, 21, 31-61. doi:10.1007/s12528-009-9011-х

Plass, J. L., Homer, B. D., Milne, C., Jordan, T., Kalyuga, S., Kim, M., \& Lee, H. J. (2009). Design factors for effective science simulations: Representation of information. International Journal of Gaming and Computer-Mediated Simulations, 1, 16-35. doi:10.4018/jgcms .2009010102
Raudenbush, S. W., Bryk, A. S., \& Congdon, R. (2011). HLM 7 for Windows [Computer software]. Skokie, IL: Scientific Software International.

Rittle-Johnson, B., \& Alibali, M. W. (1999). Conceptual and procedural knowledge of mathematics: Does one lead to the other? Journal of Educational Psychology, 91, 175-189. doi:10.1037/0022-0663.91.1.175

Rittle-Johnson, B., Siegler, R. S., \& Alibali, M. W. (2001). Developing conceptual understanding and procedural skill in mathematics: An iterative process. Journal of Educational Psychology, 93, 346-362. doi: 10.1037/0022-0663.93.2.346

Salen, K., \& Zimmerman, E. (2003). Rules of play: Game design fundamentals. Cambridge, MA: MIT Press.

Salomon, G. (Ed.). (1993). Distributed cognitions: Psychological and educational considerations. Cambridge, England: Cambridge University Press.

Scardamalia, M., \& Bereiter, C. (1991). Higher levels of agency for children in knowledge building: A challenge for the design of new knowledge media. Journal of the Learning Sciences, 1, 37-68. doi: 10.1207/s15327809j1s0101_3

Shaffer, D. W. (2008). How computers help children learn. New York, NY: Palgrave.

Sharan, S., \& Shaulov, A. (1990). Cooperative learning, motivation to learn, and academic achievement. In S. Sharan (Ed.), Cooperative learning: Theory and research (pp. 173-202). New York, NY: Praeger.

Shrager, J., \& Siegler, R. S. (1998). SCADS: A model of children's strategy choices and strategy discoveries. Psychological Science, 9, 405-410. doi:10.1111/1467-9280.00076

Skaalvik, E. (1997). Self-enhancing and self-defeating ego orientations: Relations with task and avoidance orientation, achievement, selfperceptions and anxiety. Journal of Educational Psychology, 89, 71-81. doi:10.1037/0022-0663.89.1.71

Slavin, R. E. (1980). Cooperative learning. Review of Educational Research, 50, 315-342.

Slavin, R. E. (1983). When does cooperative learning increase student achievement? Psychological Bulletin, 94, 429-445. doi:10.1037/00332909.94.3.429

Slavin, R. E. (1988). Cooperative learning and student achievement. Educational Leadership, 46, 31-33.

Slavin, R. E., Leavey, M. B., \& Madden, N. A. (1984). Combining cooperative learning and individualized instruction: Effects on student mathematics achievement, attitudes, and behaviors. Elementary School Journal, 84, 409-422. doi:10.1086/461373

Squire, K. (2003). Video games in education. International Journal of Intelligent Games \& Simulation, 2, 49-62.

Squire, K. (2005). Changing the game: What happens when video games enter the classroom. Journal of Online Education, 1, 1-20.

Squire, K. (2008). Open-ended video games: A model for developing learning for the interactive age. In K. Salen (Ed.), The ecology of games (pp. 167-198). Cambridge, MA: MIT Press.

Steinkuehler, C. A. (2006). Massively multiplayer online videogaming as participation in a discourse. Mind, Culture \& Activity, 13, 38-52. doi:10.1207/s15327884mca1301_4

Stipek, D. J., \& Kowalski, P. (1989). Learned helplessness in task-orienting versus performance orienting testing conditions. Journal of Educational Psychology, 81, 384-391. doi:10.1037/0022-0663.81.3.384

Strommen, E. F. (1993). "Does yours eat leaves?" cooperative learning in an educational software task. Journal of Computing in Childhood Education, 4, 45-56.

Tas, Y., \& Tekkaya, C. (2010). Personal and contextual factors associated 2025 with students' cheating in science. The Journal of Experimental Education, 78, 440-463. doi:10.1080/00220970903548046

Tronsky, L. N. (2005). Strategy use, the development of automaticity, and working memory involvement in complex multiplication. Memory \& Cognition, 33, 927-940. doi:10.3758/BF03193086 
Um, E., Plass, J. L., Hayward, E. O., \& Homer, B. D. (2012). Emotional design in multimedia learning. Journal of Educational Psychology, 104, 485-498. doi:10.1037/a0026609

Urdan, T., \& Mestas, M. (2006). The goals behind performance goals. Journal of Educational Psychology, 98, 354-365. doi:10.1037/00220663.98.2.354

van Bruggen, J. M., Kirschner, P. A., \& Jochems, W. (2002). External representation of argumentation in CSCL and the management of cognitive load. Learning and Instruction, 12, 121-138.

Vygotsky, L. S. (1978). Mind in society: The development of higher psychological processes. Cambridge, MA: Harvard University Press.
Yackel, E., Cobb, P., \& Wood, T. (1991). Small-group interactions as a source of learning opportunities in second-grade mathematics. Journal for Research in Mathematics Education, 22, 390-408. doi:10.2307/ 749187

Received December 15, 2011 Revision received January 28, 2013 Accepted March 4, 2013

\section{New Editors Appointed, 2015-2020}

The Publications and Communications Board of the American Psychological Association announces the appointment of 6 new editors for 6-year terms beginning in 2015. As of January 1, 2014, manuscripts should be directed as follows:

- Behavioral Neuroscience (http://www.apa.org/pubs/journals/bne/), Rebecca Burwell, PhD, Brown University

- Journal of Applied Psychology (http://www.apa.org/pubs/journals/apl/), Gilad Chen, PhD, University of Maryland

- Journal of Educational Psychology (http://www.apa.org/pubs/journals/edu/), Steve Graham, EdD, Arizona State University

- JPSP: Interpersonal Relations and Group Processes (http://www.apa.org/pubs/journals/psp/), Kerry Kawakami, PhD, York University, Toronto, Ontario, Canada

- Psychological Bulletin (http://www.apa.org/pubs/journals/bul/), Dolores Albarracín, PhD, University of Pennsylvania

- Psychology of Addictive Behaviors (http://www.apa.org/pubs/journals/adb/), Nancy M. Petry, PhD, University of Connecticut School of Medicine

Electronic manuscript submission: As of January 1, 2014, manuscripts should be submitted electronically to the new editors via the journal's Manuscript Submission Portal (see the website listed above with each journal title).

Current editors Mark Blumberg, PhD, Steve Kozlowski, PhD, Arthur Graesser, PhD, Jeffry Simpson, $\mathrm{PhD}$, Stephen Hinshaw, $\mathrm{PhD}$, and Stephen Maisto, $\mathrm{PhD}$, will receive and consider new manuscripts through December 31, 2013. 